\title{
ANALISIS EFISIENSI USAHATANI STROBERI (Fragaria $x$ ananassa) (Studi Kasus: Desa Dolat Rakyat Kecamatan Dolat Rakyat Kabupaten Karo)
}

\author{
Oleh: \\ Asmina Herawaty Sinaga ${ }^{1)}$ \\ Firman Laia ${ }^{2)}$ \\ Universitas Darma Agung, Medan ${ }^{1,2)}$ \\ E-mail : \\ Asminaherawaty67@gmail.com $^{1)}$ \\ firmanlaia97@gmail.com $^{2)}$
}

\begin{abstract}
The purpose of this study is (1) to analyze the amount of strawberry ushatani income, starting from production, selling price, revenue to net income, (2) analyzing the level of optimization of the use of inputs on strawberry farming, (3) knowing the feasibility of strawberry ushatani, is it worth the effort or not. The amount of income of a sample farmer is influenced by age, farming experience and the number of production factors used. The everage strawberry production in the study area is $1,077,915 \mathrm{~kg}$ with an average land area of 0,23 $\mathrm{H}$. The income and income of sample farmers also have an importent effect on the selling price of production, where the everage selling price of farmers in the study area is quite large, namely Rp25,000 / kg. The everage acceptance of sample farmers in the study area is Rp26,947,875 with an average production cost of Rp21,292,126 so that it receives an average net income of Rp5,655,749/year. And this very low when compared to UMK Karo of Rp2,619,234.41. Strawberry farmers in the study area mostly have a fairly low aducation of 9 years, therefore farmers have minimal knowledge in cultivation and marketing techniques and also the lack of farmers in terns of farm management that does not take into account the supporting factors of farming and use more than one (1), sucs as pesatisida with
\end{abstract}


the same function so that it will increase production costs, as well as low access to farmers's capabilites in government and banking policies.

Keywords : optomization, strawberry.

\begin{abstract}
ABSTRAK
Besarnya pendapatan seorang petani sampel dipengaruhi oleh umur, pengalaman bertani dan jumlah faktor yang digunakan. Rata-rata produksi stroberi di daerah penelitian adalah $1.077,915 \mathrm{~kg}$ dengan rata-rata luas lahan 0,23 ha. Penerimaan dan pendapatan petani sampel juga berpengaruh penting dengan harga jual produksi, dimana harga jual rata-rata petani di daerah penelitian cukup besar yaitu Rp. 25.000/kg. Rata -rata penerimaan petani sampel di daerah enelitian sebesar Rp. 26.947.875 dengan rata-rata biaya produksi sebesar Rp. 21.292.126 sehingga mendapatkan pendapatan bersih rata-rata sebesar Rp. 5.655.749/tahun. Dan ini sangat rendah sekali jika dibandingkan dengan UMK Karo sebesar Rp. 2.619.234,41. Petani stroberi di daerah penelitian Sebagian besar mempunyai pendidikan yang cukup rendah yaitu 9 tahun, oleh karena itu petani memiliki pengetahuan yang minim dalam teknik budidaya dan pemasaran dan juga minimnya petani dalam hal manajemen usahatani yang tidak memperhitungkan faktor-faktor pendukung usahatani dan menggunakannya lebih dari satu (1), seperti pestisida dengan fungsi yang sama sehingga akan menambah biaya produksi, serta rendahnya akses kemampuan petani dalam kebijakan pemerintah dan perbankan.
\end{abstract}

Kata kunci: optimasi dan stroberi.

\section{PENDAHULUAN}

Tanaman stroberi berasal dari benua Amerika. Nikolai Ivanovich Vavilov, seorang ahli botani yang berasal dari Uni Soviet, pada tahun 1887-1942 telah melakukan ekspedisi ke Asia, Afrika, Eropa dan Amerika, beliau berkesimpulan bahwa tanaman stroberi berasal dari daerah Chili. Jenis atau spesies stroberi yang pertama kali ditemukan di Chili adalah Fragaria chiloensis 
(L). Duchesne atau disebut stroberi Chili.

Budidayanya telah dirintis berabad-abad tahun yang lalu. Sekitar pada tahun 50-an para pakar pertanian dan biologi Amerika merintis permuliaan tanaman (plant breeding) stroberi bertujuan untuk menghasilkan atau menciptakan varietas baru. Pada tahun 1600ansalah satu jenis tanaman stroberi, yaitu F.moschata dibudidayakan di Skandinavia, Eropa Timur dan sampai meluas ke Rusia. Selama beberapa abad F.vesca sangat populer sebagai tanaman pekarangan, selanjutnya menyebar di Asia Utara dan Amerika Utara.

\section{Faktor Produksi}

\section{a. Benih}

Benih adalah biji tanaman vang sengaja di produksi dengan teknik-teknik tertentu sehingga memenuhi persyaratan untuk digunakan sebagai bahan pertanaman selanjutnya

\section{b. Pupuk}

Pupuk merupakan bahan yang diberikan ke dalam tanah baik organik maupun non organik dengan maksud untuk mengganti kehilangan unsur hara dan dalam tanah dan bertujuan untuk meningkatkan produksi tanaman dalam keadaan faktor keliling atau lingkungan baik.

\section{c. Pestisida}

Pestisida merupakan bahan yang digunakan dalam mengendalikan hama dan penyakit tanaman stroberi

\section{d. Tenaga Kerja}

Tenaga kerja merupakan faktor produksi yang penting dan perlu diperhitungkan dalam proses produksi. Tenaga kerja lebih penting dan faktor produksi lain seperti bibit, tanah, dan air, sebab manusialah yang menggerakkan faktor-faktor tersebut untuk menghasilkan suatu jenis barang. Dalam usaha tani curahan tenaga kerja yang tepat akan memberikan dampak positif terhadap peningkatan produksi usaha.

$$
\text { Untuk melihat apakah }
$$
usahatani layak diusahakan dan dikembangkan, maka digunakan analisis revenue cost ratio (R/C) sebagai berikut :

$$
\begin{aligned}
& \text { R/C ratio }= \\
& \frac{\text { Total penerimaan }(T R)}{\text { Total biaya produksi }(T C)}
\end{aligned}
$$


dimana :

Revenue = besarnya

biaya penerimaan yang

diperoleh

Cost = besarnya

biaya yang dikeluarkan

Ada tiga kriteria dalam

perhitungan, yaitu :

a. Apabila R/C > 1 artinya

usahatani tersebut

menguntungkan

b. Apabila $\mathrm{R} / \mathrm{C}=1$ artinya

usahatani tersebut impas

c. Apabila $\mathrm{R} / \mathrm{C}<1$ artinya

usahatani tersebut rugi

\section{TINJAUAN PUSTAKA}

Dewasa ini produksi buah stroberi (Fragaria $x$ ananassa) di dunia telah menghasilkan 650.000 ton setiap tahunnya. Negara produsen dan pengekspor stroberi (Fragaria $x$ ananassa) terbesar saat ini antara lain Amerika Serikat, Jepang, Meksiko, Polandia dan Italia. Pada perkembangan selanjutnya, baik secara cepat maupun lambat daerah-daerah yang beriklim tropis pun mulai menaru perhatian pada agribisnis tanaman stroberi
(Fragaria $x$ ananassa) (Kanisius, 1999).

Tanaman stroberi (Fragaria $x$ ananassa) di Indonesia sebenarnya telah lama ditanam semenjak penjajahan dahulu, tetapi sampai saat ini penyebaran dan budidaya stroberi (Fragaria x ananassa) belum meluas ke daerah-daerah diseluruh Indonesia. Padahal tanaman lainnya seperti komoditi jeruk, apel dan anggur sudah berkembang. Manfaat stroberi (Fragaria x ananassa) selain sumber vitamin dan mineral untuk memnuhi kebutuhan gizi manusia juga mempunyai nilai ekonomi yang patut diperhitungkan.

Beberapa faktor yang mendukung keberhasilan sutau usaha agribisnis adalah adanya teknologi, adanya modal dan produk tersebut laku untuk dijual artinya dibutuhkan oleh konsumen. Pada masing-masing subsektor agribisnis terdapat beberapa komoditas unggulan yang penentuannya berdasarkan pangsa pasar, nilai ekonomi, sebaran wilayah produksi dan kesesuaian agroekolgi. Pemberian pupuk akan berpengaruh terhadap prodksi pertain Marpaun R \& Pasaribu B (2020). 
Buah stroberi (Fragaria $x$ ananassa) mempunyai rasa khas manis dan menyegarkan selain warnanya yang menarik, stroberi (Fragaria $x$ ananassa) juga memiliki kandungan nutrisi yang cukup lengkap sehingga memiliki daya ketertarikan pada setiap pengusaha atau pecinta rasa stroberi (Fragaria $x$ ananassa).

\section{METODE PELAKSANAAN}

Pada penelititan, penentuan besarnya sampel dan populasi dapat dihitung dengan menggunakan rumus Solvin (Sevilla dan Consuelo, 1933) yaitu :

$\mathrm{n}=\frac{N}{1+\left(N(M \circ \theta)^{2}\right)}$

Analisis untuk efisiensi ekonomis digunakan rumus sebagai berikut :

$$
\mathrm{EE}=\mathrm{ET} . \mathrm{EH}
$$

Dimana :

$\mathrm{EE}=$ Efisiensi ekonomis

$\mathrm{ET}=$ Efisiensi teknis

$\mathrm{EH}=$ Efisiensi harga(Alokatif)

Dengan kriteria uji : a. Jika ET . EA > 1, maka penggunaan faktor produksi belum (kurang) efisiensi sehingga perlu ditambahkan penggunaan faktor produksi.

b. Jika ET . EA = 1, sudah mencapai efisien.

c. Jika ET . EA < 1, tidak (lebih) efisien sehingga perlu dikurangi

\section{HASIL PENELITIAN DAN}

\section{PEMBAHASAN}

Berdasarkan

hasil pengamatan rata-rata harga jual sebesar Rp. 25.000/kg dan jumlah harga sarana produksi dapat dilihat pada tabel 1 .

Tabel 1. Tingkat Efisiensi Teknis di

Daerah Penelitian, Tahun 2018

\begin{tabular}{|c|c|c|c|c|c|}
\hline $\mathbf{N}$ & $\begin{array}{c}\text { Inpu } \\
\mathbf{t}\end{array}$ & NPM & $\mathbf{P x}$ & $\begin{array}{c}\mathbf{N P} \\
\mathbf{M} / \mathbf{P} \\
\mathbf{x}\end{array}$ & $\begin{array}{l}\text { Krit } \\
\text { eria }\end{array}$ \\
\hline 1 & $\begin{array}{l}\text { Beni } \\
\text { h }\end{array}$ & $\begin{array}{l}12.23 \\
8,81\end{array}$ & $\begin{array}{l}1.0 \\
00\end{array}$ & 12,24 & $\begin{array}{l}\text { Belu } \\
\mathrm{m} \\
\text { Efisi } \\
\text { en }\end{array}$ \\
\hline 2 & $\begin{array}{l}\text { Pupu } \\
\mathrm{k} \\
\text { Urea }\end{array}$ & $\begin{array}{l}- \\
3.539 \\
, 11\end{array}$ & $\begin{array}{l}1.5 \\
00\end{array}$ & $-2,35$ & $\begin{array}{l}\text { Tida } \\
\mathrm{k} \\
\text { Efisi }\end{array}$ \\
\hline
\end{tabular}




\begin{tabular}{|c|c|c|c|c|c|}
\hline & & & & & en \\
\hline 3 & $\begin{array}{l}\text { Pupu } \\
\text { k } \\
\text { TSP }\end{array}$ & $\begin{array}{l}10.82 \\
4,65\end{array}$ & $\begin{array}{l}3.0 \\
00\end{array}$ & 3,6 & $\begin{array}{l}\text { Belu } \\
\mathrm{m} \\
\text { Efisi } \\
\text { en }\end{array}$ \\
\hline 4 & $\begin{array}{l}\text { Pupu } \\
k \\
\text { NPK }\end{array}$ & $\begin{array}{l}- \\
10.23 \\
6,83\end{array}$ & $\begin{array}{l}2.3 \\
00\end{array}$ & $-4,45$ & $\begin{array}{l}\text { Tida } \\
\mathrm{k} \\
\text { Efisi } \\
\text { en }\end{array}$ \\
\hline 5 & $\begin{array}{l}\text { Pesti } \\
\text { sida } \\
\text { Durs } \\
\text { ban }\end{array}$ & $\begin{array}{l}133,2 \\
7\end{array}$ & $\begin{array}{l}35 . \\
000\end{array}$ & 0,004 & $\begin{array}{l}\text { Tida } \\
\mathrm{k} \\
\text { Efisi } \\
\text { en }\end{array}$ \\
\hline 6 & $\begin{array}{l}\text { Pesti } \\
\text { sida } \\
\text { Mars } \\
\text { al }\end{array}$ & 65,45 & $\begin{array}{l}75 . \\
000\end{array}$ & 0,008 & $\begin{array}{l}\text { Tida } \\
\mathrm{k} \\
\text { Efisi } \\
\text { en }\end{array}$ \\
\hline 7 & $\begin{array}{l}\text { Pesti } \\
\text { sida } \\
\text { Scor } \\
\text { e }\end{array}$ & $\begin{array}{l}- \\
80,35\end{array}$ & $\begin{array}{l}57 . \\
500\end{array}$ & 0,001 & $\begin{array}{l}\text { Tida } \\
\mathrm{k} \\
\text { Efisi } \\
\text { en }\end{array}$ \\
\hline
\end{tabular}

Hasil perhitungan nilai harga atau berdasarkan tabel yang mana dapat dijelaskan bahwa rata-rata penggunaan faktor produksi secara alokatif belum efisien sehingga produksi stroberi yang dihasilkan juga belum optimal karena memiliki nilai rata-rata efisiensi harga lebih besar daripada satu(>1).

Efisiensi maupun keuntungan ditentukan oleh nilai produksi yang dihasilkan, sedangkan nilai produksi ditentukan secara bersama-sama oleh faktor input yaitu input variable yang terdiri dari benih, pupuk dan pestisida.

\section{Pengujian} efesiensi penggunaan faktor produksi melalui pendekatan fungsi produksi disajikan pada tabel 2 .

Tabel 2. Efesiensi Ekonomis Penggunaan Faktor-Faktor Produksi pada Usahatani Stoberi di Daerah Penelitian, Tahun 2018

\begin{tabular}{|l|l|l|l|}
\hline Input & $\begin{array}{l}\text { Efesiensi } \\
\text { Teknis }\end{array}$ & $\begin{array}{l}\text { Efesiensi } \\
\text { Harga }\end{array}$ & $\begin{array}{l}\text { Efesiensi } \\
\text { Ekonomis }\end{array}$ \\
\hline Benih & 12,24 & 5,01 & 61,32 \\
\hline Pupuk Urea & $-2,35$ & $-15,93$ & 37,43 \\
\hline Pupuk TSP & 3,6 & 30,04 & 108,14 \\
\hline Pupuk NPK & $-4,45$ & $-34,99$ & 155,7 \\
\hline $\begin{array}{l}\text { Pestisida } \\
\text { Dursban }\end{array}$ & 0,004 & 8,43 & 0,033 \\
\hline $\begin{array}{l}\text { Pestisida } \\
\text { Marsal }\end{array}$ & 0,008 & 2,94 & 0,023 \\
\hline $\begin{array}{l}\text { Pestisida } \\
\text { Score }\end{array}$ & $-0,001$ & $-3,63$ & 0,0036 \\
\hline
\end{tabular}

Sumber : Data diolah 
Dari tabel 2 dapat disimpulkan bahwa pemberian faktor-faktor produksi pada usahatani stroberi di daerah penelitian untuk faktor produksi belum efesien secara ekonomis, karena nilai efesiensi ekonomis lebih besar daripada satu.

Keterbatasan sumberdaya setiap produsen atau petani berusaha menekan biaya serendah mungkin sehingga memberikan keuntungan maksimal. Tingkat output yang diperoleh dari kombinasi penggunaan input yang demikian disebut output dan input yang optimal. Suatu input yang digunakan secara optimal apabila penggunaan input tersebut sampai jumlah tertentu nilai output terakhir yang dihasilkan hanya cukup membayar harga input yang digunakan tersebut.

Seringkali dijumpai makin luas lahan yang dipakai sebagai usaha pertanian akan semakin tidak efesien lahan tersebut. Hal ini didasarkan pada pemikiran bahwa luasnya lahan mengakibatkan upaya untuk melakukan tindakan yang mengarah pada segi efesiensi akan berkurang disebabkan kurangnya pengetahuan petani dalam menghitung penggunaan pupuk terhadap tanaman, sehingga akan semakin meningkat biaya produksi.

Ada anggapan pada petani bahwa pemberian pupuk akan meningkatkan produksi stroberi. Sementara penggunaan pupuk berlebihan dapat menurunkan produksi tanaman stroberi dan secara ekonomis dapat merugikan pendapatan bersih usahatani, karena besarnya biaya yang dikeluarkan untuk pengadaan saran produksi tersebut.

Untuk mengetahui kelayakan usahatani stroberi :

$\mathrm{R} / \mathrm{C}$ ratio $=$

$\mathrm{R} / \mathrm{C}$ ratio $=1.26$

Berdasarkan data diatas dapat disimpulkan bahwa R/C > 1 yang artinya usahatani layak untuk diusahakan dimana nilai R/C yaitu 1,26 .

\section{KESIMPULAN DAN SARAN}

\section{Kesimpulan}

1. Hasil analisis efisiensi faktor produksi dan sosial ekonomi 
berpengaruh nyata terhadap pendapatan per petani.

2. Hasil $\mathrm{R} / \mathrm{C}>1$ maka secara ekonomi layak untuk diusahakan.

\section{Saran}

1. Agar petani menerapkan teknologi budidaya yang lebih maju dan modern.

2. Diharapkan kepada peneliti selanjutnya agar dapat melakukan penelitian tentang pengembangan.

\section{DAFTAR PUSTAKA}

BPS, 2016, Sumatera Utara dalam Angka 2016. Badan Pusat Statistik Sumatera Utara.

BPS 2015. Statistik Sayuran Dan Buah-Buahan semusim $\underline{\text { Indonesia. }}$

Mubyarto, 2005. Pengantar Ekonomi Pertanian. Jakarta ; Pustaka LP3ES Indonesia, anggota IKAPI.

Rasihen, D. (2011, Desember 1).
Retrivied April 16, 2018, from karya ilmiah budidaya stroberi : html.

Soekartawi, 2002. Prinsip Dasar Ekonomi Pertanian (Teori dan Aplikasi). PT. Raja Grafindo Persada. Jakarta.

Suratiyah, K. 2009. Ilmu Usahatani. Jakarta : Penebar Swadaya.

Tasman, A 2008. Pengukuran Efisiensi : Pendekatan Stochastic Frontiers. MEP FE Univesitas Jambi.

Ziraah. (2015). Kegiatan dan Pendapatan Usahatani Stroberi, 198

Marpaung, R., \& Pasaribu, B. (2020). RESPON PERTUMBUHAN DAN PERKEMBANGAN SAYUR PELENG (Spinacia oleracea) TERHADAP PEMBERIAN PUPUK ORGANIK CAIR PADA BERBAGAI MULSA. Jurnal Darma Agung, 28(1), 116 $-131$.

doi:10.46930/ojsuda.v28i1.519

Karya ilmiah budidaya stroberi. 